\title{
Double-tunnel circumferential endoscopic submucosal dissection with double clip- band-line traction for an esophageal squamous neoplasm
}

Esophageal endoscopic submucosal dissection (ESD) is technically challenging [1 -5]. We report a successful circumferential esophageal ESD procedure using the double-tunnel and double-traction method with the clip-band-line technique applied on both pillars.
A 70-year-old man underwent an esophagogastroduodenoscopy for dysphagia. A suspicious $80-\mathrm{mm}$ flat lesion was detected in the middle and lower esophagus. Digital chromoendoscopy and Lugol staining was used to examine it, with characterization suggesting a non-invasive squamous cell carcinoma (SCC).
Biopsies were taken, and a computed tomography (CT) scan and endoscopic ultrasound (EUS) were negative for nodal and distal metastases. The treatment options were discussed with the patient and at a multidisciplinary committee, with the option of esophageal ESD being chosen.

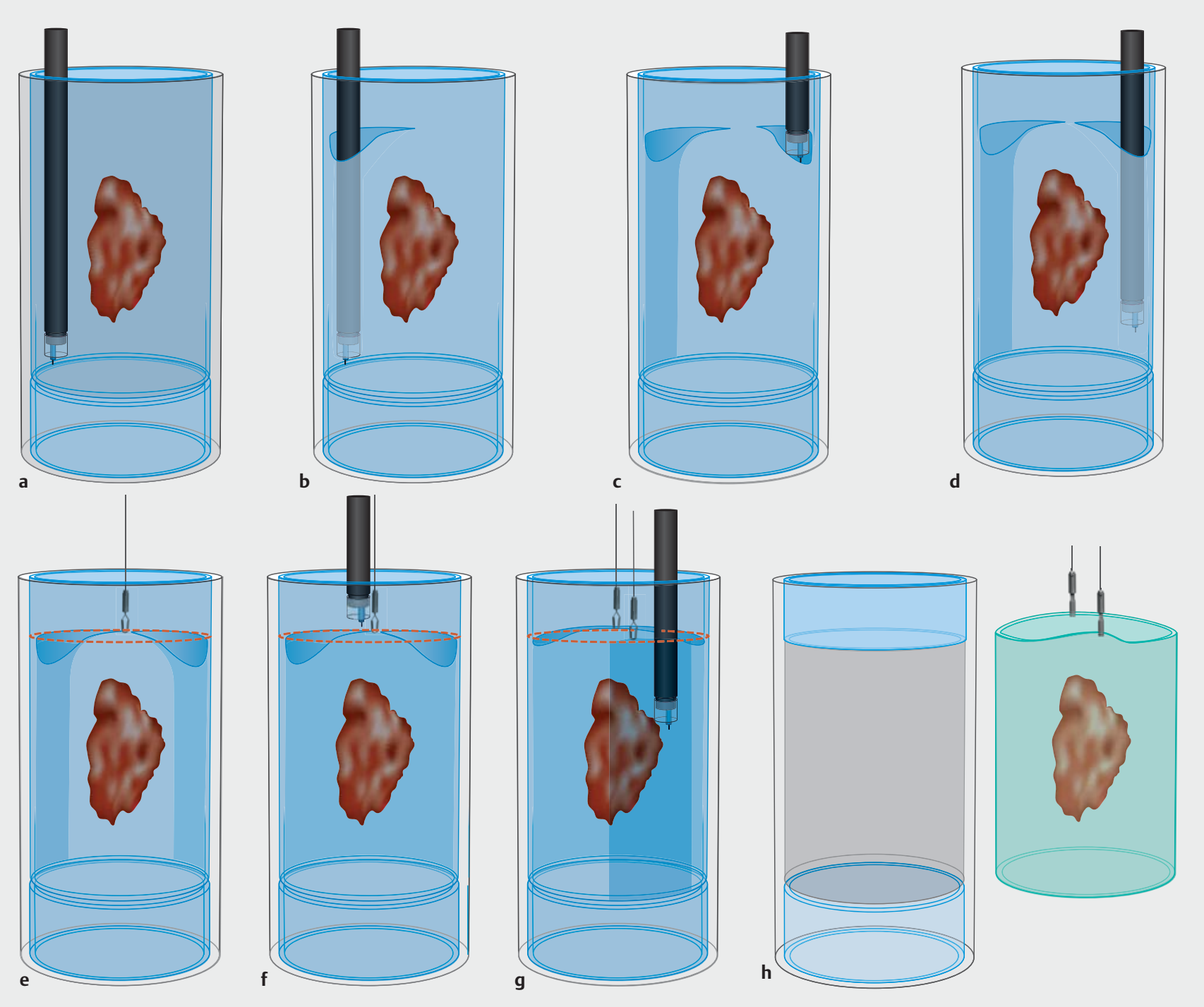

- Fig. 1 Schematic of the steps involved in the double-tunnel and double-traction method for resection of a large superficial esophageal lesion including: $\mathbf{a}$ a circumferential anal incision; $\mathbf{b}$ incision and creation of the first tunnel; $\mathbf{c}, \mathbf{d}$ the second incision and tunnel created at the opposite end of the circumference; $\mathbf{e}$ the "clip band line" placed on the first pillar; $\mathbf{f}$ dissection of the first pillar; $\mathbf{g}$ the second "clip band line" on the second pillar and dissection of the second pillar; $\mathbf{h}$ the completed circumferential endoscopic submucosal dissection. 

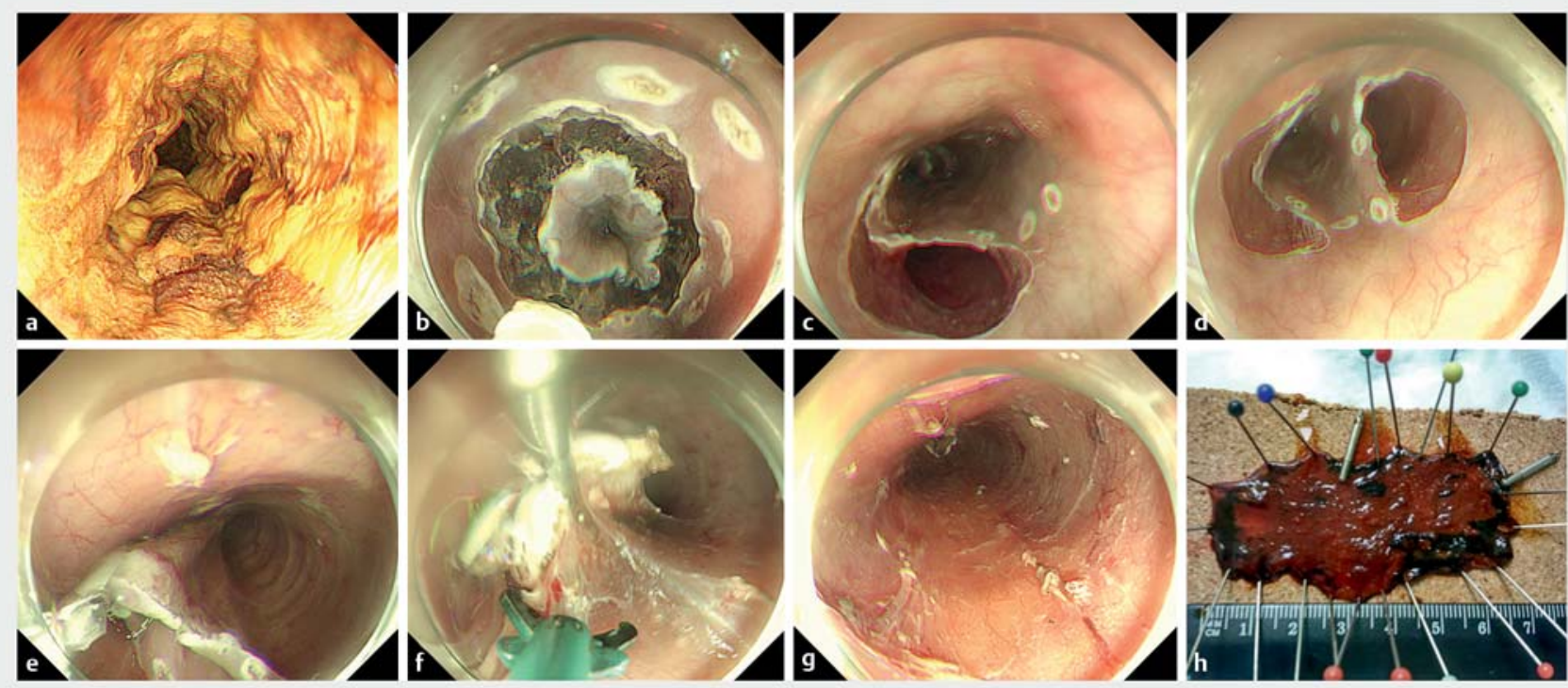

- Fig. 2 Endoscopic views during the double-tunnel and double-traction endoscopic submucosal dissection showing: a the esophageal lesion with Lugol stain; $\mathbf{b}$ the circumferential anal cut; $\mathbf{c}$ the first tunnel; $\mathbf{d}$ the second tunnel; e dissection of the first pillar with the use of clip-band-line traction; $\mathbf{f}$ dissection of the second pillar with a second "clip band line" applied; $\mathbf{g}$ the circumferential scar. $\mathbf{h}$ Macroscopic appearance of the resected specimen.

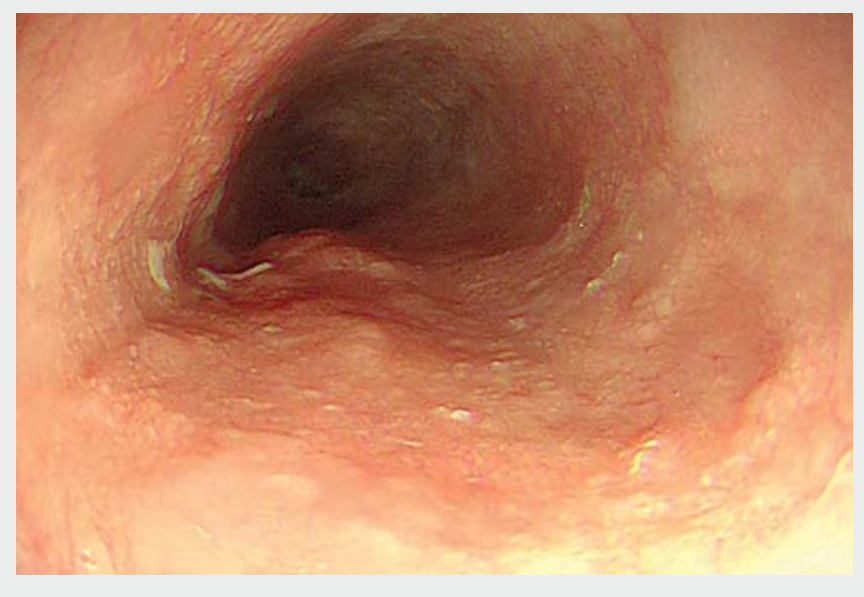

Video 1 Double-tunnel and double-traction method applied on both pillars for circumferential esophageal endoscopic submucosal dissection.

ESD was performed using a DualKnife (Olympus Corp., Japan) for the incision and tunnel creation and an SB Knife junior (Sumitomo Bakelite Co Ltd, Japan) for the dissection of the pillars. We made an anal circumferential incision with the DualKnife. Next, a submucosal tunnel was created from the oral side until the anal incision was reached. Once the first tunnel was completed, a second tunnel was made at the opposite end of the circumference. The first pillar was dissect- ed, with clip-band-line traction applied on the pillar, facilitating clear submucosal exposure. The same procedure was performed for the second pillar, also using clip-band-line traction ( $>$ Fig. 1 and - Fig. 2; Video 1).

ESD was successfully completed, achieving an "en bloc" resection after 230 minutes. The specimen showed an SCC with invasion of the lamina propria only and with negative margins (T1, R0). After 8 weeks, a stenosis was detected and the patient has since received four pneumatic dilations up to $15 \mathrm{~mm}$.

In conclusion, double-tunnel ESD with clip-band-line traction applied to both pillars facilitated the safe resection of a large superficial circumferential neoplasm.

Endoscopy_UCTN_Code_TTT_1AO_2AN

Competing interests

The authors declare that they have no conflict of interest.

The authors

Miguel Fraile-López ${ }^{1,2}$, Adolfo Parra-Blanco ${ }^{2}$

1 Department of Gastroenterology, Hospital Universitario Central de Asturias, Oviedo, Spain

2 NIHR Nottingham Biomedical Research Centre, Department of Gastroenterology, Nottingham University Hospitals NHS Trust and University of Nottingham, Nottingham, UK 


\section{Adolfo Parra-Blanco, MD, PhD}

Endoscopy Unit, Nottingham City Hospital Campus, Nottingham University Hospitals NHS Trust, Hucknall Rd, Nottingham, NG5 $1 \mathrm{~PB}, \mathrm{UK}$

Fax: +44-115-8405821

Adolfo.Parra-Blanco@nottingham.ac.uk

\section{References}

[1] Abe S, Oda I, Suzuki H et al. Insulated tip knife tunneling technique with clip line traction for safe endoscopic submucosal dissection of large circumferential esophageal cancer. VideoGIE 2017; 2: 342-345

[2] Arantes V, Albuquerque W, Freitas Dias CA et al. Standardized endoscopic submucosal tunnel dissection for management of early esophageal tumors (with video). Gastrointest Endosc 2013; 78: 946-952
[3] Linghu E, Feng X, Wang X et al. Endoscopic submucosal tunnel dissection for large esophageal neoplastic lesions. Endoscopy 2013; 45: 60-62

[4] Jacques J, Legros R, Rivory J et al. The "tunnel + clip" strategy standardised and facilitates oesophageal ESD procedures: a prospective, consecutive bi-centric study. Surg Endosc 2017; 31: 4838-4847

[5] Oyama T. Esophageal ESD: technique and prevention of complications. Gastrointest Endosc Clin N Am 2014; 24: 201-212

\section{Bibliography}

DOI https://doi.org/10.1055/a-1109-2365

Published online: 21.2.2020

Endoscopy 2020; 52: E303-E305

(c) Georg Thieme Verlag KG

Stuttgart · New York

ISSN 0013-726X
ENDOSCOPY E-VIDEOS

https:/|eref.thieme.de/e-videos

口回 Endoscopy E-Videos is a free Fection, reporting 田: on interesting cases and new techniques in gastroenterological endoscopy. All papers include a high quality video and all contributions are freely accessible online.

This section has its own submission website at https://mc.manuscriptcentral.com/e-videos 